\title{
INVESTIGATING THE IMPACT OF INTERNET OF THINGS ON EGYPTIAN
} PORTS SUSTAINABILITY

\author{
ENGY BAYOUMI ${ }^{1}$, SARA ELGAZZAR ${ }^{1}$, MATEVZ OBRECHT ${ }^{2}$ \\ ${ }^{1}$ College of International Transport and Logistics at Arab Academy for Science, Technology and \\ Maritime Transport, Alexandria,Egypt,engyosman48@gmail.com,sara.elgazzar@aast.edu \\ ${ }^{2}$ Department of Managing Logistics and Supply Chain, Faculty of Logistics, University of \\ Maribor, MariborskaCesta 7,3000 Celje,Slovenia, matevz.obrecht@um.si
}

\begin{abstract}
There are increasing concerns on the environmental impact of port operations which resulted in pressing global issues such as adopting sustainable technologies to reduce environmental harmful impacts on ports. From the sustainability perspective, a port should manage and balance three aspects which are economic, social, and environmental impacts. Using Internet of things (IoT) technology could minimize the environmental harmful impacts on ports and increase their sustainability. This paper aims at investigating the impact of applying IoT technology on Egyptian ports' sustainability. A semi structured interview was conducted with a representative sample of different stakeholders (government, port authority, freight forwarders, importers and exporters), upon which the main challenges and obstacles to adopt IoT technology in the Egyptian ports were identified. The paper concluded with suggestions and recommendations to help practitioners to consider the applicability of IoT technology as a sustainability driver in the Egyptian ports.
\end{abstract}

Keywords: port sustainability, Internet of things, Egyptian ports

\section{INTRODUCTION}

Environmental issues such as scarcity of resources, environmental pollution, global warming and decrease in biological diversity cause harming to the ecological balance. These ecological problems are increasing continuously to the extent that enforced governments, organizations and individuals to take precautions in environmental matters to maintain sustainability. International and national laws have recently been more restricted with organizations contributing to environmental problems and developed procedures in order to enforce them to change their production processes and supply chains to be more green and environmental friendly (Çankaya and Sezen, 2019).

The fourth industrial revolution has a tremendous impact on the digitalized environment and the environmental sustainability. Internet of things (IoT) is considered one of the core technologies related to the fourth industrial revolution. It facilitates all the supply chain operations to be more efficient and green with low costs on the long term and with higher quality products and services (Kayikci, 2018). It provides many applications in the fields of smart ports, smart transportation, smart energy, waste management and smart logistics (Ahmed, 2017).

Port traditional operations (such as cargo handling, loading and discharging, waste management) could cause environmental pollutions such as leakage, waste emissions and noise. Automating operations in ports by using technologies such as IoT could increase sustainability and reduce emissions (Figueiredo et al., 2017).

The purpose of this research is to investigate the impact of applying IoT on ports' sustainability. The paper starts in section two with review of previous studies to show the importance of IoT and the main barriers that may hinder its applicability. Semistructured interview methodology was presented and conducted in sections three and four respectively to examine the benefits of IoT and its applicability in The Egyptian 
ports. Finally the paper concluded in section five by proposing suggestions to facilitate IoT adoptability in The Egyptian ports.

\section{LITERATURE REVIEW}

The fourth industrial revolution is the era of automation and digitalization. The fourth industrial revolution tools such as Internet of Things (IoT) will increase transparency, enhance efficiency, and reduce the inefficient use of time (Adeniran, 2018). The application of IoT and the connected devices is increasing each year (Jović, 2019).

Internet of Things (IoT) is "a sophisticated technology with several applications and services in everyday life and in every field. IoT aims at penetrating our everyday environment and its objects, linking the physical world to the digital world and allowing people and devices to be connected anytime, anywhere, with anything and with anyone". IoT solutions can be applied to all fields and environments such as transportation and logistics field which includes sophisticated devices and applications for tracking, RFIDs in warehouses and assisted driving devices (Lampropoulos et al., 2019).

Ports are very complex industry because of their nature, offered services and a wide range of environmental issues such as harmful emissions, waste and noise production and pollution (Hakam, 2015). They are consisting of different companies, dealing with different activities and offering a wide range of services. Seaports are notably known to be very polluting industry. However, they have many opportunities for reducing emissions and pollutions (Broesterhuizen et al., 2012). Sustainability in the port industry is of growing source of fear for port authorities, policy makers, port users and local communities; which makes sustainability a one of the important concepts for port industry (Özispa and Arabelen, 2018).

With the development of the IoT, a growing area in academic research focuses on smart ports. They find some implications on how to enable intelligence of the port and they highlighted the principles of creativity in the smart sustainable development of port areas (Siror et al., 2011). In addition, there are key performance indicators guiding the evaluation of smart ports, involving the energy utilization rate, application of energy saving and low carbon technology, and the carbon intensity of port equipment, showing the challenges and obstacles in transformation into smart seaports (Ferretti and Schiavone, 2016).

An automated port consists of the sophisticated logistics solutions to enhance containers management, traffic flows, terminal and parking slot capacities. IoT enable to share information between terminal staffs and ship's crew about the ship capacity, the number of containers, the duration of stopover at port, etc. (Belfkih et al., 2017).

Moreover, IoT can help port workers to take the right planning decisions which improve the time of load and unload of containers and reduce the risk of damage. Also, using wireless sensors, fixed on the containers, enable data collection about containers before load and unload cargo to improve the containers management in the terminals and move them to the designated places, which reduces unnecessary moves, logistics time and costs. It also allows tracking containers of dangerous goods and facilitates the accesses control device by customs. IoT technology can also reduce the number of empty containers which enhance the terminal storage capacities (Dong et al., 2013). 
From the sustainability perspective, a port should manage and balance three aspects which are economic, social, and environmental impacts. From economic perspective, IoT provides real time monitoring and maximising the economic performance by increasing the port operations efficiency. Moreover, IoT will result in cost efficiency in the long run as all processes will be automated. The impact of applying IoT on social sustainability is mainly contributing to the enhancement and the monitoring of people's quality of life by supporting port activities to satisfy socio-economic priorities such as employment opportunities with safety precautions, education for employees and communities, and improving social stability of the area surrounding ports (Narula, 2014). While environmental sustainability can be achieved by applying IoT through minimising the negative impacts caused by a wide range of operational and shipping activities within the ports such as energy and resources used. So, this will minimize wastes and hence, all port practices will be green (Lim et al., 2018).

As indicated in the previous discussion, the automated ports that utilize IoT technology in their operations possesses many advantages especially in saving labour costs, improving the operation efficiency and economic benefits, reducing energy consumption, improving the level of safe operation, and promoting the image of the port and even the image of the city (Minh et al., 2012). According to estimations, the automated ports can save at least $25 \%$ more energy and reduce $15 \%$ more carbon emissions than the traditional ports (Yang et al., 2018).

Despite the benefits of IoT and its advantages, there are problems regarding the use of this technology such as security, privacy, and legal aspects. Keeping security and privacy in IoT devices must be a fundamental priority. Users need to trust that IoT devices and related data services are secure from attacks. Low secured IoT devices can expose user data to theft by leaving data streams inadequately protected. Accordingly, a collaborative approach to security will be needed to develop effective and appropriate solutions to IoT security challenges (Shakara et al., 2017).

There are also other barriers to implement IoT, such as high cost of implementation. IoT applications require designing IoT devices with centralized cloud-based business model. This requirement is very expensive and it would take years to cover its expenses, and then generate revenues. Also the lack of knowledge to users about implementing IoT could be challenging and time cost, and effort consuming (Bandyopadhyay and Sen, 2011). Moreover, lack of infrastructure is one of the greatest barriers that hinder the application of IoT. In addition, lack of universally agreed-upon standards is another problem to adopt IoT technology (Joshi, 2018).

Egypt has a strategic geographical location at the crossroads of Europe, Africa and Asia. Egypt lies between two major seas: the Mediterranean Sea, which provides a route to Europe and North America, and the Red Sea, which continues on to the Indian Ocean. In addition, the two seas are linked by the Suez Canal which is rendered as a major trade hub between Europe and Asia (Hafez and Madney, 2020).

Egyptian ports includes 15 commercial ports; 2 ports in Alexandria (Alexandria port and El-Dekheila port), 6 ports in Red Sea Ports Authority (Suez port, Hurghada port, Safaga port, Sharm El-Sheikh port, Nuwaiba port, Petroleum Dock port), 6 ports in Suez Canal Zone (Port-Said port, East Port-Said port, Sokhna port, El-Tour port, Arish port, Adabiya port), and Damietta port. Moreover, Egypt has 33 specialized ports in mining, petroleum, tourist and fishing. These ports are characterized by their strategic geographical locations and the availability of promising investment projects at the coming years and hence, this increases their competitive advantage (Maritime Transport Sector, 2020).

https://doi.org/10.24264/icams-2020.III.3 
Although the potentiality of Egyptian ports to lead worldwide, till now most of the Egyptian ports' operations are un-automated, this could be of a great importance to implement IoT applications in the Egyptian ports' operations.

This section highlighted the importance of IoT implementation in ports operations as well as its barriers and challenges, while showing the vital role it could play to contribute to the Egyptian ports competitiveness and sustainability. The next two sections will illustrate the methodology used in this paper to investigate the current situation of Egyptian ports concerning the automation procedures and IoT applicability, followed by suggestions to speed up and enable IoT applicability in the Egyptian ports operations.

\section{METHODOLOGY}

The research used a qualitative data collection strategy through conducting semi structured interviews to investigate IoT impacts on Egyptian ports and the main obstacles that may hinder its application in order to conclude with suggestions to overcome these obstacles. The semi structured interviews were conducted with a sample from the Egyptian port industry representing different stakeholders (Egyptian government, port authority, freight forwarders, importers and exporters) in order to obtain comprehensive discussion and analysis. First, the interview questions were developed based on the extensive literature review illustrated in the previous section. Then, pilot interviews were carried out with two operators at the Egyptian ports to get new unforeseen ideas about IoT implementation in Egyptian ports and verify the interview questions. Finally, a semi structured interview was conducted with five interviewees representing the main stakeholders in Egyptian port sector. The interview design includes 6 questions discussing: the impact of IoT on the 3 pillars of sustainability (environmental, economic and social), the barriers and challenges that hinder the application of IoT applications in the Egyptian ports and how to overcome them, and the interviewees suggestions to facilitate IoT application in the Egyptian ports.

\section{DISCUSSION OF RESULTS}

\section{Evaluation of the Impact of IoT on Environmental Sustainability in Egyptian Ports}

The interviewees believe that applying IoT could help in reducing emissions of using traditional equipment and vessel emissions due to lack of automation. For instance, if all containers on board the vessels were connected by sensors, the time of vessel arrival would be more accurate and hence, congestion in ports would decrease which will lead to less emissions. Also it will lead to less human interventions as they stated that the main reasons for environmental pollution are human and documents. The interviewees gave an example of Covid-19 and how it showed complications to handle ports operations in the traditional way with documents and un-automated operations. While if IoT was implemented, it would help in the continuity of the port operations without human intervention and without pollution. 


\section{Evaluation of the Impact of IoT on the Social and the Economic Aspects}

The interviewees agreed on implementing IoT in Egyptian ports would help in the social and the economic development. For the social impacts, IoT will reduce human congestion at the port as they commented that in Egyptian ports there are many customers supervise their shipments by themselves which lead to useless human congestions in ports. While IoT and automated systems could help them finish and track their shipments remotely, and hence, safety and security to them will increase.

For the economic impacts, the international trade in Egypt will increase because the operation itself will be more accurate, efficient and with less mistakes. Accordingly, the revenues of the authority will increase and thus the competitive advantage of the Egyptian ports will improve. The interviewees gave an example about port of Port-Said in Egypt as it is considered as an automated port compared to other ports in Egypt and customers prefer to receive their shipments from it because the process of receiving their shipment is easier and automated.

\section{The Barriers Hinder the Application of IoT in Egypt}

The interviewees summarize the barriers of applying IoT in Egyptian ports in 3 main barriers. Firstly, the high cost of implementation in the short run. IoT implementation will cost a lot in the short run, but when looking for the long run, it will cover its costs by generating huge amount of revenues. The second barrier is the lack of knowledge to many operators and it would be challenging and time-consuming to train them, in addition to the resistance to change. The third barrier is custom clearance in Egypt because it is $100 \%$ un-automated and it is the first process that customers do when they receive their shipment. The interviewees argued that the custom clearance workers will not be willing to change their process because IoT applications and systems are not unified and not standardized so many conflicts will happen.

\section{Suggested Tools that Could Be Used to Solve the Lack of Knowledge Barrier}

The interviewees stated that operators in Egypt are willing to do anything in order to get the business done. Once they learn something, they just follow it. So, if they are well prepared, by giving them appropriate seminars or on the job training, this will lead to the required capacity building. On the other hand, the interviewees commented that drivers and old operators might refuse to change their operations.

\section{The Influence of Privacy and Security Concerns on Applying IoT}

The interviewees believe that security concerns are a big issue because operators will not feel safe giving any information to any person to put on a device or an application. Also, if someone hack the sensors or the applications, it would be a problem because the port operations will be delayed and hence, a huge demurrage will be paid. Moreover, the operators and customers personal information will be hacked. Therefore in order to build such application, a well set plan on how legally it will be controlled is a must.

\section{Suggestions to Implement IoT in the Egyptian Ports}

The interviewees recommend to apply IoT in Egyptian ports partially as a pilot on one or two operations first (such as in cargo handling and transportation processes 
inside the port) in order to assess the results, and get the operators familiar with these technologies. Once the operators will witness the benefits of IoT applications especially in terms of the revenues that they will gain on the long run and the positive environmental impacts, this will encourage them to extent IoT applications to all port operations.

Another point they raised as a main trigger to speed up the implantation of IoT is considering the security aspects of the platform and data bases to gain the trust of the operators and other stakeholders. Moreover they said that Egypt has to unify the rules of transport operations and custom clearance in order to facilitate the implement of IoT.

\section{CONCLUSION}

IoT and digitization tools could provide seaports better monitoring to achieve sustainability and reduce the negative environmental, social and economic impacts. However, there are some risks and barriers could face the implementation of IoT such as the privacy concerns, the unified rules and the lack of knowledge from all parties in the port industry.

The paper provided a procedure to investigate the impact of applying IoT on the 3 pillars of sustainability and to suggest solutions to facilitate its applicability which can be adopted by other researchers in other countries. The interviews findings provided suggestions and insights that can help practitioners and decision makers in the Egyptian port industry to apply IoT technology as a sustainability driver in the Egyptian ports.

Further research can investigate how to solve the obstacles of IoT implementations identified in this research. Also a comparative research method can be employed to compare between countries already applied IoT technology and applications in their ports and Egypt in order to identify the gap analysis and lesson learned to shape a road map for Egyptian ports towards IoT implementation.

\section{REFERENCES}

Adeniran, A.O. (2018), "Impacts of the Fourth Industrial Revolution on Transportation in the Developing Nations”, International Educational Scientific Research Journal, 2(11), 56-60.

Ahmed, E.S. (2017), "Internet of Things Applications, Challenges and Related Future Technologies", World Scientific News International Journal, 67(2), 126-148, eISSN 2392-2192, 21, available online at www.worldscientificnews.com.

Bandyopadhyay, D. and Sen, J. (2011), "Internet of Things: Applications and Challenges in Technology and Standardization”, Wireless Personal Communications, 58, 49-69, https://doi.org/10.1007/s11277-0110288-5.

Belfkih, A., Duvallet, C. and Sadeg, B. (2017), "The Internet of Things for Smart Ports Application to the Port of Le Havre", Proceedings of IPaSPort 2017, 15-16.

Broesterhuizen, E., Vellinga, T., Docters van Leeuwen, L., Zwakhals, J.W., Taneja, P. and Nijdam, M (2012), "Sustainability as a procurement criterion for port investments", Third International Engineering Systems Symposium CESUN 2012, Rotterdam, The Netherlands.

Çankaya, S.Y. and Sezen, B. (2019), "Effects of green supply chain management practices on sustainability performance", Journal of Manufacturing Technology Management, 30(1), 98-121, https://doi.org/10.1108/JMTM-03-2018-0099.

Dong, X., Xiong, G., Li, Y., Guo, X. and Lv, Y. (2013), "Intelligent Ports Based on Internet of Things", Proceedings of 2013 IEEE International Conference on Service Operations and Logistics, and Informatics, https://doi.org/10.1109/SOLI.2013.6611428.

Ferretti, M. and Schiavone, F. (2016), "Internet of Things and business processes redesign in seaports. The case of Hamburg”, Business Process Management Journal, 22(2), https://doi.org/10.1108/BPMJ-052015-0079.

https://doi.org/10.24264/icams-2020.III.3 
Figueiredo, A.P., Carvalhal, R.D., Hoeflich, S., Figueiredo, L., Pereira, S.L. and Dias, E.M. (2017), "Port operation - increase of automated systems, decline of workforce jobs?", Recent Advances in Computer Science, 259-266.

Hafez, R.M. and Madney, I. (2020), "Suez Canal Region as an economic hub in Egypt location analysis for the mass real estate appraisal process", HBRC Journal, 16(1), 59-75, https://doi.org/10.1080/16874048.2020.1734347.

Hakam, M.H. (2015), "Nordic Container Port Sustainability Performance-A Conceptual Intelligent Framework", Journal of Service science and Management, 8(1), 14-23, https://doi.org/10.4236/jssm.2015.81002.

Joshi, N. (2018), "Due to these 5 Barriers, companies hesitate to adopt IoT", retrieved from https://www.allerin.com/blog/due-to-these-5-barriers-companies-hesitate-to-adopt-iot.

Jović, M., Tijan, E., Aksentijević, S. and Čišić, D. (2019), “An Overview of Security Challenges of Seaport IoT Systems", 42nd International Convention on Information and Communication Technology, Electronics and Microelectronics (MIPRO), 1571-1576, https://doi.org/10.23919/MIPRO.2019.8757206.

Kayikci, Y. (2018), "Sustainability impact of digitization in logistics", 15th Global Conference on Sustainable Manufacturing (p. 8), Beykoz, Istanbul, Turkey, Procedia Manufacturing, 21, 782-789, https://doi.org/10.1016/j.promfg.2018.02.184.

Lampropoulos, G., Siakas, K. and Anastasiadis, T. (2019), "Internet of Things in the Context of Industry 4.0: An Overview", International Journal of Entrepreneurial Knowledge, 7(1), 4-19, https://doi.org/10.37335/ijek.v7i1.84.

Lim, S., Pettit, S., Abouarghoub, W. and Beresford, A. (2019), "Port sustainability and performance: a systematic literature review", Transportation Research Part D: Transport and Environment, 72, 47-64, https://doi.org/10.1016/j.trd.2019.04.009.

Maritime Transport Sector (2020), retrieved from Maritime transport sector (MTS): http://www.mts.gov.eg/en.

Minh, L.H., Yassine, A. and Riadh, M. (2012), "Scheduling of lifting vehicle and quay crane in automated port container terminals", Intern. J. Intelligent Inform. Database Syst, 6(6), 516-531, https://doi.org/10.1504/IJIIDS.2012.050092.

Narula, K. (2014), "Emerging Trends in the Shipping Industry-Transitioning Towards Sustainability", Maritime Affairs: Journal of the National Maritime Foundation of India, 10(1), 113-138, https://doi.org/10.1080/09733159.2014.928473.

Özispa, N. and Arabelen, G. (2018), "Sustainability issues in ports: content analysis and review of the literature (1987- 2017)", SHS Web of Conferences, 58, 01022 https://doi.org/10.1051/shsconf/20185801022.

Shakara, A.H., Hasan, M.T. and Akter, N. (2017), "Solutions of common challenges in IoT", IOSR Journal of Computer Engineering, 19(5), 57-65, https://doi.org/10.9790/0661-1905055765.

Siror, J.K., Huanye, S. and Dong, W. (2011), "RFID based model for an intelligent port", Comput. Ind, 62(8 9), 795-810, https://doi.org/10.1016/j.compind.2011.08.004.

Yang, Y., Zhong, M., Yao, H., Yu, F., Fu, X. and Postolache, O. (2018), "Internet of things for smart ports: Technologies and challenges", IEEE Instrumentation \& Measurement Magazine, 21(1), 34-43, https://doi.org/10.1109/MIM.2018.8278808. 
Investigating the Impact of Internet of Things on Egyptian Ports Sustainability

https://doi.org/10.24264/icams-2020.III.3 